\title{
PROPOSTA METODOLÓGICA DE DANÇA PARA CRIANÇAS COM DEFICIÊNCIA INTELECTUAL
}

Flávia Regina Ferreira Alves, Universidade Federal de Juiz de Fora - UFJF, Juiz de Fora, Minas Gerais - Brasil

Flávia Ceccon Moreira Gil, Universidade Federal de Juiz de Fora - UFJF, Juiz de Fora, Minas Gerais - Brasil

Carolina Lessa Cataldi, Universidade Federal de Juiz de Fora - UFJF, Juiz de Fora, Minas Gerais - Brasil

Otávio Rodrigues de Paula, Universidade Federal de Juiz de Fora-UFJF, Juiz de Fora, Minas Gerais - Brasil

Eliana Lúcia Ferreira, Universidade Federal de Juiz de Fora - UFJF, Juiz de Fora, Minas Gerais - Brasil

\section{RESUMO}

$\mathrm{O}$ artigo pautou na busca de uma visão multidisciplinar em benefício de crianças com deficiência intelectual, através de uma proposta metodológica utilizando a dança através do movimento e da interação com o corpo. As atividades foram realizadas com alunos com deficiência intelectual na escola estadual Maria das Dores de Souza, (Juiz de Fora-MG) e o objetivo era desenvolver um método de dança para esta população com base no estudo das práticas corporais inclusivas. A metodologia baseou-se na observação das atividades motoras através da dança, com o propósito de criar uma proposta para melhoria do atendimento de alunos com deficiência intelectual. A criança que apresenta a deficiência intelectual não desenvolve no mesmo ritmo em relação às crianças que não apresentam a deficiência. $O$ desenvolvimento é tardio em relação às crianças com a mesma idade cronológica. Esse desenvolvimento tardio não é apenas na área da educação, é também na aprendizagem de habilidades, nas ações básicas do cotidiano e nos limites sociais. Concluímos que a dança terapêutica promoveu um feedback motivacional para a prática desportiva e proporcionou um aperfeiçoamento no desempenho motor, melhoras no seu relacionamento com a dança em cadeira de rodas, na imagem corporal e uma melhor qualidade de vida.

Palavras-Chave: Deficiência intelectual; Dança; Atividades motoras.

\section{METHODOLOGICAL PROPOSAL OF DANCE ACTIVITY FOR PEOPLE WITH INTELLECTUAL DISABILITIES}

\footnotetext{
ABSTRACT

This paper was based on a search for a multidisciplinary vision in favor of people with intellectual disability, exploiting a methodological proposal in which the dance will act throughout the movement and interaction with the body. The research activities were 
performed with students who have intellectual disabilities and are attending the State school Maria das Dores, at Juiz de Fora, in Minas Gerais. The goal of this research was to develop a method of dancing with these people based on the study of inclusive practices for people with disabilities. The methodology was based on the observation of motor activities in the course of dance, with the purpose of creating a proposal to ameliorate the service offered to the students with intellectual disabilities. Kids who have intellectual disabilities do not have the same development as other kids with the same age. This late development is not related to the educational sphere only, but it is also related to the learning of other abilities, to the basic actions of daily life and the social limits. We concluded that the therapeutic dance promoted a motivational feedback to the sportive practice and provided a motor improvement, such as enhancements in their relationship with the wheelchair, better body image and better life quality.

Key-Words: Intellectual disability; Dance; Motor activities.

\section{PROPUESTA METODOLOGÍA DE DANZA PARA NIÑOS CON DISCAPACIDAD INTELECTUAL}

\section{RESUMEN}

El artículo partió en la búsqueda de una visión multidisciplinar en beneficio de los niños con discapacidad intelectual, a través de una propuesta metodológica que utiliza la danza a través del movimiento y de la interacción con el cuerpo. Las actividades fueron realizadas con alumnos con discapacidad intelectual en la escuela estatal Maria das Dores de Souza (Juiz de Fora-MG) y el objetivo era desarrollar un método de danza para esta población con la base de las prácticas corporales inclusivas. La metodología se basó en la observación de las habilidades motoras a través de la danza, con el propósito de crear una propuesta de mejora para la atención de alumnos con discapacidad intelectual. El niño que presenta discapacidad intelectual no se desarrolla al mismo ritmo en relación a los niños que no presentan discapacidad. El desarrollo tardío no es apenas un área de la educación, también lo es el aprendizaje de habilidades y las acciones básicas de la vida diaria en sus límites sociales. Como conclusión señalar que la danza terapéutica promovió un feedback motivacional para la práctica deportiva y proporcionó un perfeccionamiento del desempeño motor, mejoras en su relación con la danza en silla de ruedas, en la imagen corporal y en la mejora de la calidad de vida.

Palabras-Clave: Discapacidad intelectual; Danza; Actividades motoras. 


\section{INTRODUÇÃO}

Estudos como o de Ferreira, ${ }^{1}$ tem demonstrado que a dança para/com as pessoas com deficiência é um lugar possível de instituir sociabilidades, subjetividades e identidades. Esta modalidade, praticada pelas pessoas com deficiência tem provocado um embate contra aqueles que preconizam dança enquanto perfeição estética.

Nesta mesma linha argumentativa, Tavares, ${ }^{2}$ diz que esta prática corporal proporciona prazer, quebra de paradigmas e pode levar a não padronização do movimento e à criação de novas realidades corpóreas.

No Brasil, a consolidação dos trabalhos de dança para as pessoas com deficiência tem-se dado principalmente pela perseverança dos dançarinos em desenvolver esta modalidade e suas necessidades de abrir espaços com a possibilidade de se expressar, marcando assim, as diferenças artísticas/sociais.

Esta possibilidade de um novo paradigma artístico é reflexo das tendências sempre mutantes da arte e da dança, inseridas num processo mais amplo de mudanças sociais. Portanto, a dança para as pessoas com deficiência, é uma possibilidade de dança. No entanto, ainda é preciso quebrar com resistências teóricas e práticas sobre as metodologias de dança, que se construíram ao longo dos anos, visando a construção de corpos perfeitos.

Para Ferreira, ${ }^{3}$ "quem dança realiza movimentos que possuem sentidos e significados em si mesmos, e que são recriados, revividos, a cada momento." Corroborando com a autora, Mello, ${ }^{4}$ conclui que esta atividade, além de promover processos terapêuticos, serve como contribuinte nos processos de aprendizagem e profissionalizante, no desenvolvimento da criatividade e principalmente na relação do praticante com o mundo, tornando-se uma força propulsora de mudanças e transformações na vida cotidiana das pessoas.

Tendo em vista os benefícios estudados e apontados em diversas literaturas, não é de se admirar que a dança, hoje, se mostre cada vez mais importante quando se trata de atividades para pessoas com deficiência. Cada vez mais, vemos sua interferência na 
inserção e reintegração social destas pessoas, podendo dizer que a dança com caráter inclusivo contribui no propósito do crescimento do ser humano, além da redescoberta de seu corpo e da própria identidade.

As crianças, de um modo geral, apresentam características diversas no decorrer do seu desenvolvimento, sendo que, para cada uma das etapas, existe um determinado tempo de aprendizagem. No entanto, sabe-se que isto é mais acentuado quando a criança apresenta deficiência intelectual (DI).

A Organização Mundial da Saúde (OMS), ${ }^{5}$ através de testes psicrométricos, identifica como deficiente intelectual, o individuo que apresenta dois desvios padrões abaixo da média de sua população correspondente, o que equivale a um quociente de inteligência (QI) inferior a 70.

Diante desta classificação, as pessoas com deficiência intelectual apresentam algumas características muito peculiares e distintas, que interferem diretamente na sua aprendizagem e no seu desenvolvimento motor. De um modo geral, pessoas com deficiência intelectual demonstram mais lentidão, com significativa perda de força, resistência, agilidade, equilíbrio, velocidade, flexibilidade e tempo de reação.

Os problemas motores apresentados por essa população derivam de fatores externos e de ordem maturacional diretamente ligados à estrutura do organismo e às mudanças que nele ocorrem. ${ }^{5}$ Deste modo, dependendo do contexto das experiências vivenciadas, a pessoa com deficiência intelectual pode apresentar melhoras a partir de atividades motoras, em especial, a partir da vivência dos elementos que constituem a construção pedagógica da dança de um modo geral.

Nesta linha de raciocínio, Gimenez, ${ }^{6}$ nos alerta que um programa destinado às crianças com deficiência intelectual com grau de comprometimento leve e moderado, deve dar preferência, a um trabalho que visa o aperfeiçoamento das capacidades motoras.

Partindo da concepção de que todo sujeito apresenta potencialidades, apesar das mais variadas dificuldades que lida em seu dia a dia, e que elas devem ser exploradas na Conexões: revista da Faculdade de Educação Física da UNICAMP, Campinas, v. 10, n. 3, p. 101-112, set./dez. 2012 . 
descoberta de si mesmo, inserimos a dança como uma possível autora da reescrita do corpo da pessoa com deficiência intelectual, pois todo sujeito é capaz de dançar, de alguma forma e de acordo com suas condições individuais.

À medida que cresce, a criança assimila as formas de dança de seu grupo social. Por vivenciar essa prática em festividades ao longo de sua vida, ela associa prazer e diversão e aprende a se integrar aos demais membros de sua comunidade através das diversas maneiras de dançar. ${ }^{7}$ Soares, ${ }^{8: 88}$ et al. enfatizam:

Que o corpo deformado pela doença se encontra distante do modelo de beleza socialmente aceito e procurado; assim, o interesse do outro por este corpo passa a se interpretado como um distúrbio.

Na educação tradicional da dança, a predominância de técnicas clássicas trabalhava um corpo padronizado e virtuoso através de passos e posturas altamente codificados, que deveriam ser apreendidos a partir da simples repetição de movimentos pré-concebidos. Reconhecendo essas ações como um problema que limitava a potência expressiva do corpo, Angel Vianna buscou estudar o corpo com a finalidade de descobrir um melhor acesso a ele, para poder ampliar suas potencialidades. Esse modo autêntico de lidar com o corpo nos campos da Arte e Educação, acabou direcionando o que se chamou de Conscientização do Movimento, para uma utilidade também terapêutica e de reabilitação neuromotora, ${ }^{9}$ aplicada há anos, por várias instituições de reabilitação, com importantes ganhos secundários mais subjetivos, tais como bem-estar psíquico, sentimento de que o corpo está vivo e potente, apesar das limitações físicas etc.

Segundo Gândara, ${ }^{10}$ a dança que acompanha o Homem desde o início dos tempos, através de sua história e em todos os momentos de sua existência, demonstra que as emoções e os sentimentos podem ser manifestados pelas crianças com deficiências por meio do movimento, das danças folclóricas nacionais e internacionais, das rodas cantadas e dos exercícios ritmados de coordenação motora, superando as dificuldades adquiridas pela deficiência, tais quais: integridade física, confiança nos sentidos, mobilidade, atividades da vida diária, percepção visual do belo e do agradável, recreação, segurança financeira, independência pessoal, adaptação social, autoestima e organização total da personalidade. 
Os estudos apontam que a dança deve ser praticada pelas pessoas com deficiência e as pesquisas como as de Boff et al. ${ }^{11}$ e Zimmerman et al., ${ }^{12}$ têm demonstrado a relevância e importância desta modalidade para pessoas com deficiência intelectual. No entanto, quando se fala em dança para pessoas com deficiência intelectual, não se encontra grupos específicos para tal prática e nem metodologias próprias que respeitem a diferença desta população. Sendo assim, o presente estudo tem como objetivo desenvolver uma metodologia de ensino da dança para as pessoas com deficiência intelectual com base nos estudos de Ferreira, ${ }^{13-15}$ que aponta uma proposta de dança para pessoas com deficiência física. Utilizamos estes estudos como parâmetros, pois é um método que prioriza a individualidade corporal de cada de um de seus dançarinos.

\section{METODOLOGIA}

O presente estudo descritivo qualitativo, foi aprovado pelo comitê de Ética da UFJF. Nele consta a proposta, a partir de uma pesquisa de campo e estudos teóricos e bibliográficos, de uma metodologia de dança para pessoas com deficiência intelectual.

A pesquisa de campo ocorreu em uma escola especial pública, da cidade de Juiz de Fora/MG, no decorrer de 03 anos. Esta pesquisa foi realizada com 50 crianças e adolescentes de ambos os sexos e com idade entre 08 a 15 anos, que apresentam deficiência intelectual.

Foi construído um diário de campo e neste, foram anotados os procedimentos e as avaliações realizadas, bem como a descrição das atividades e o desempenho dos alunos.

\section{Proposta metodológica de dança}

O trabalho de campo desenvolvido no decorrer dos últimos 3 anos, foi copilado e organizado de forma a estabelecer uma estratégia temporal de ensino que foi elaborada para auxiliar o processo de ensino-aprendizagem da prática corporal em questão.

Neste sentido, a primeira estratégia empregada foi a de utilizar sequências fixas, que são repetidas ao longo das aulas. Esse recurso é necessário em virtude do comprometimento cognitivo das pessoas com DI e pela característica de baixa memória de curto prazo. Essa 
estratégia foi eficiente, pois, com a repetição, a criança refinou cada vez mais seus movimentos, além de proporcionar uma memorização continua.

A segunda estratégia utilizada foi o uso de imagens. Essa utilização das imagens deu-se pela associação de movimentos com imagens concretas, como por exemplo, soltar o ar como se estivesse soprando uma vela. Como o primeiro, esse recurso também se mostrou eficiente, pois, além de tornar a atividade mais atrativa, a ação pode ser concretizada, já que as pessoas com deficiência intelectual possuem dificuldade em relacionar o real com o abstrato.

Como terceira estratégia, temos a exploração do espaço, que visou o deslocamento e a exploração dos níveis espaciais. Sua eficiência se deu pelo fato do espaço ser a continuação, a extensão e o reflexo da imagem da pessoa e do próprio corpo.

A última estratégia usada foi o reconhecimento do ritmo. Através dela, buscamos identificar as diferenças de ações rápidas e lentas, buscando conter os movimentos, muitas vezes descontrolados.

Todas estas quatro estratégias mencionadas acima foram trabalhadas a partir de vivencias práticas. Segundo Castro, ${ }^{16}$ para o aluno com DI as instruções das atividades devem ser condicionadas ao grau de complexidade verbal e nível atencional de cada um.

\section{Proposta metodológica de dança para pessoas com deficiência intelectual}

Diante das nossas experiências apresentaremos uma proposta de dança para crianças com DI. A qual, para efeitos didáticos, dividimos o trabalho em seis fases. A saber:

a) Fase I: Conhecer e ser conhecido: esta é a primeira e a principal fase do desenvolvimento da dança para pessoas com DI. É assim denominada por ser o primeiro contato professor/aluno, aluno/professor, aluno/aluno e aluno/espaço. Nesta fase, ocorrerá a observação dos alunos, ou seja, suas reações em relação ao professor, aos outros alunos. O objetivo principal aqui, não são as atividades em si, nem o desempenho dos participantes, mas sim conhecê-los, suas habilidades e dificuldades; 
b) Fase II: Ser e Estar: Consiste em conhecer e reconhecer o espaço para deslocamento corporal;

c) Fase III: Eu e o Outro: constitui-se da aplicação de atividades lúdicas e de lazer, que visam sempre trabalhar a coordenação psicomotora dos alunos. Os objetivos são a possibilidade de análise contínua dos participantes e a compreensão do desenvolvimento e da coordenação psicomotora dos mesmos, bem como, o estímulo a essa habilidade. As atividades utilizadas no presente estudo e que servem de exemplos foram piques, corridas, exercícios de saltos, exercícios de solo, estafetas, brincadeiras de roda, jogos coletivos, jogos lúdicos, exercícios psicomotores, jogos populares, corridas com mudança de direção e atividades de equilíbrio. Os alunos, de maneira geral, apresentaram uma resposta satisfatória nesta fase, apesar das dificuldades motoras;

d) Fase IV: Musicalidade: nesta fase, é trabalhado o processo de musicalidade dos alunos. Devemos ficar atentos para a escolha do repertório a ser utilizado, de acordo com a faixa etária de cada turma e o nível de compreensão das mesmas. Também é necessário permitir e incentivar que os próprios alunos escolham músicas de suas preferências, trabalhando assim a socialização, a autonomia e a capacidade de escolha do grupo em questão;

e) Fase V: Forma e movimento: este é o momento no qual o aluno vivencia as possibilidades de movimentos corporais padronizados e seqüenciais. A utilização de materiais colabora no entendimento do que vem a ser construção e desconstrução de gestos corporais;

f) Fase VI: Coreográfica: A fase coreográfica é a unificação de todas as fases. A coreografia é, neste sentido, a culminância de todo o processo desenvolvido e dos resultados obtidos ao longo do trabalho, já que, o alicerce do trabalho de dança se apoia principalmente, nas emoções e sentimentos de quem dança, e não somente no movimento físico. Segundo Ferreira, ${ }^{13}$ é importante ressaltar que o principal no trabalho da dança para a pessoa com deficiência intelectual é a própria pessoa. Nesta perspectiva, os gestos corporais significam valores, objetivos e mudanças sociais. 
Gostaríamos de ressaltar que as atividades motoras para as pessoas com DI devem-se estender a todas as idades e tem como benefícios, ampliar as capacidades físicas dessa população, as habilidades específicas e as habilidades do cotidiano, não esquecendo que devem ser prazerosas. Deste modo, ao se oferecer atividades motoras a esse público, devese ponderar, primeiramente, suas preferências, para em seguida, observar a idade cronológica dos participantes, relacionando-a a idade funcional e mental dos mesmos. Esta interseção entre idade cronológica e mental é extremamente eficaz, pois estimula os deficientes na medida certa, sem subestimar suas capacidades motoras ou superestimá-las.

Tendo em vista as colocações acima, algumas características se tornam essenciais em um programa de atividades motoras para atender, adequadamente, às pessoas com deficiência intelectual. A primeira delas é a priorização de um tempo de reação simples, que consiste em tarefas de respostas rápidas a um único estímulo, podendo este, ser visual, auditivo, sensorial, etc. Outro ponto importante é considerar o tempo de reação de escolha, presente nas atividades de respostas diferentes de acordo com o estímulo apresentado. Em seguida, podemos citar como foco de atenção, o ritmo, que aparece nas atividades que necessitam de ajustes manipulativos ou locomotivos rápidos e depende de respostas a estímulos sonoros externos e à agilidade.

Através dos movimentos corporais, destacamos que a consciência rítmica das crianças com DI acabou gerando uma maior expressão corporal nas suas relações com o tempo e o espaço, descobrindo diferentes maneiras de expressão e, consequentemente, novos caminhos para a aprendizagem motora.

As atividades físicas que envolvem habilidades e esportes também são eficientes com a população em questão, pois proporcionam prazer e obtenção de sucesso.

\section{CONCLUSÃO}

Mediante a teoria e as vivências práticas desenvolvidas na escola trabalhada, concluímos que a proposta de dança para pessoas com deficiência intelectual, vai muito além do simples aprendizado de uma arte. Foi possível perceber, logo nos primeiros meses de atividade, os variados benefícios proporcionados por ela, entre eles, uma melhora na 
estabilidade emocional dos praticantes, que passaram a demonstrar menos agressividade, mais iniciativa em suas atitudes e maior confiança em suas habilidades específicas.

Do mesmo modo, o trabalho também atingiu a criatividade dos alunos, onde se pode perceber a mudança e crescimento nas criações de movimentos próprios, fugindo dos modelos oferecidos inicialmente. Além disso, após o início das atividades, os alunos se mostraram muito mais expressivos, tanto emocionalmente quanto corporalmente.

Devido ao fato de terem sido utilizadas inúmeras ações corporais básicas, como saltar, quadrupedar, correr, girar, entre outras ações no desenvolvimento da dança, o desenvolvimento das habilidades motoras básicas foi visível, se compararmos cada participante consigo mesmo, no decorrer dos anos de trabalho.

No que tange as relações sociais, os alunos sempre foram estimulados durante as aulas, a manterem contato direto uns com os outros, a respeitarem as regras e a observarem a movimentação corporal de cada pessoa presente no mesmo espaço, o que influenciou, sobremaneira, a socialização de todos.

Diante dessa aceitação, podemos dizer que a prática da dança apresenta contribuições extremamente significativas no amadurecimento e desenvolvimento das pessoas com deficiência intelectual.

Vale ressaltar que a dança como meio de inserção social para os deficientes desmistifica a idéia de impotência e impossibilidade.

Desta forma, a dança de um modo geral, passa a ter representatividade social, ou seja, passa a ter sentidos e ao mesmo tempo estabelece e constitui outros sentidos para a dança e a deficiência. Muitas pessoas com deficiência estão se reconhecendo na dança. Esta tem sido uma possibilidade de se estar em sociedade. Desta forma, a dança pode ser um elemento de equilíbrio social para as pessoas com deficiência e/ou possibilidade de transformação pessoal e social.

\section{REFERÊNCIAS}

Conexões: revista da Faculdade de Educação Física da UNICAMP, Campinas, v. 10, n. 3, p. 101-112, set./dez. 
${ }^{1}$ FERREIRA, E. L. Proposta metodológica para o desenvolvimento da dança em cadeira de rodas. Conexões: Educação Física Esporte Lazer, Campinas, v. 1, n. 6, p. 37-46, 2001.

${ }^{2}$ TAVARES, V. P.; FERREIRA, E. L. Análise do desenvolvimento da dança em cadeira de rodas no Brasil. In: SIMPÓSIO INTERNACIONAL DE DANÇA EM CADEIRA DE RODAS, 4., Juiz de Fora, 2005. Anais... Juiz de Fora, 2005.

${ }^{3}$ FERREIRA, E. L. Dança em cadeira de rodas: Um espaço de materialidades múltiplas, densas, latentes. In: SIMPÓSIO INTERNACIONAL DE DANÇA EM CADEIRA DE RODAS, 4., Juiz de Fora, 2005. Anais... Juiz de Fora, 2005.

${ }^{4}$ MELLO, M. T. O desenvolvimento da atividade de pesquisa científica no âmbito da dança em cadeira de rodas: aspectos psicobiológicos. In: In: SIMPÓSIO INTERNACIONAL DE DANÇA EM CADEIRA DE RODAS, 1., Campinas, 2001. Anais... Campinas: Unicamp, 2001. p. 88-90.

${ }^{5}$ ORGANIZAÇÃO MUNDIAL DE SAÚDE. (OMS). The ICD-10 classification of mental and behavioral disordes: clinical descriptions and diagnostic guidelines. Genebra, 1992

${ }^{6}$ GIMENEZ, R.; MANOE, E. J. Comportamento motor e deficiência: considerações para pesquisa e intervenção. In: TANI, G. Comportamento motor aprendizagem e desenvolvimento. Rio de Janeiro: Guanabara Koogan, 2005.

\section{${ }^{7}$ ALBINATI, M. E. C. B. Recursos musicais aplicados à saúde e à educação da criança} e do adolescente: contribuições da musicoterapia à clínica pediátrica. 2008. Tese (Doutorado em Medicina) - Faculdade de Medicina, Universidade Federal de Minas Gerais, Belo Horizonte, 2008.

${ }^{8}$ SOARES, A. H. R. et al. A qualidade de vida de jovens portadores de espinha bífida do Children's National Medical Center - Washington DC. Ciências e Saúde Coletiva, Rio de Janeiro, v. 11, n. 3, jul./set. 2006.

Conexões: revista da Faculdade de Educação Física da UNICAMP, Campinas, v. 10, n. 3, p. 101-112, set./dez. 
${ }^{9}$ RESENDE, C. O que pode um corpo? O método Ângel Vianna de conscientização do movimento como um instrumento terapêutico. Physis: revista de saúde coletiva, Rio de Janeiro, v. 18, n. 3, set. 2008.

${ }^{10}$ GÂNDARA, M. A expressão corporal do deficiente corporal. Campinas: Cip - Brasil, 1993.

${ }^{11}$ BOFF, S. R. A influência da dança no desenvolvimento da coordenação motora em crianças com Síndrome de Down. Conexões: revista da Faculdade de Educação Física da UNICAMP, Campinas, v. 6, ed. especial, p. 144-154, jul. 2008.

${ }^{12}$ ZIMMERMAN, E. B.; MESQUITA, K. Dança: estímulo ao desenvolvimento de crianças portadoras de deficiência mental. Revista Digital Art, v. 5, abr. 2006

${ }^{13}$ FERREIRA, E. L. et al. (Org.). Interfaces da dança para pessoas com deficiência. Campinas: CBDCR, 2002.

${ }^{14}$ FERREIRA, E. L.; FERREIRA, M. B. R. A possibilidade do movimento corporal na dança em cadeira de rodas. Revista Brasileira de Cinesiologia e Movimento, Brasília, v. 12, n. 4, dez. 2004.

${ }^{15}$ FERREIRA E. L. Dança em cadeira de rodas. In: FERREIRA E. L. (Org.). Atividade Física, deficiência e inclusão escolar. Niterói: Intertexto, 2010.

${ }^{16}$ CASTRO, E. M. Atividade física adaptada. São Paulo, 2005. 